\title{
Models and mosaics: Investigating cross-cultural differences in risk perception and risk preference
}

\author{
ELKE U. WEBER \\ Columbia University, New York, New York \\ and \\ CHRISTOPHER K. HSEE \\ University of Chicago, Chicago, Illinois
}

\begin{abstract}
In this article, we describe a multistudy project designed to explain observed cross-national differences in risk taking between respondents from the People's Republic of China and the United States. Using this example, we develop the following recommendations for cross-cultural investigations. First, like all psychological research, cross-cultural studies should be model based. Investigators should commit themselves to a model of the behavior under study that explicitly specifies possible causal constructs or variables hypothesized to influence the behavior, as well as the relationship between those variables, and allows for individual, group, or cultural differences in the value of these variables or in the relationship between them. This moves the focus from a simple demonstration of cross-national differences toward a prediction of the behavior, including its cross-national variation. Ideally, the causal construct hypothesized and shown to differ between cultures should be demonstrated to serve as a moderator or a mediator between culture and observed behavioral differences. Second, investigators should look for converging evidence for hypothesized cultural effects on behavior by looking at multiple dependent variables and using multiple methodological approaches. Thus, the data collection that will allow for the establishment of conclusive causal connections between a cultural variable and some target behavior can be compared with the creation of a mosaic.
\end{abstract}

Since its beginnings as Völkerpsychologie in 19thcentury Germany, cross-cultural psychology has never been able to establish itself as something more than a minor subdiscipline of psychology (see Cole, 1996, Chap. 1, for a brief history). Its contributions are largely confined to books, edited volumes, and its own speciality journals, which are not widely read by mainstream psychologists. Yet, the argument, put forth by cross-cultural psychologists, that all conclusive psychological investigation must involve comparisons of behavior across cultures seems hard to refute.

Given the complexities of human life and the importance of culture as a behavioral determinant, it obviously behooves psychologists to test the cross-cultural generality of their principles before considering them established. (Segall, Dasen, Berry, \& Poortinga, 1990, p. 37)

So long as one does not evaluate the possible cultural variability of the psychological processes one studies, it is im-

This research was supported by Grant SBR-9631860 from the National Science Foundation. We thank Kwok Leung, Doug Medin, Paul Slovic, Pete Suttmeier, and Frank Yates for valuable discussions related to the topic of the paper. Correspondence concerning this article should be addressed to E. U. Weber. Columbia University, MC-550I, $1190 \mathrm{Am}-$ sterdam Ave., New York, NY 10027 (e-mail: elke@psych.columbia.edu). possible to know whether such processes are universal or specific to particular cultural circumstances. (Coles, 1996, p. 2)

Culture has been shown to influence a wide range of basic psychological processes. Segall, Campbell, and Herskovitz (1966) demonstrated that members of different cultures have different susceptibilities to optical illusions and color perception. Markus and Kitayama (1991) examined cultural differences in people's construal of the self. Morris and Peng (1994) observed cultural differences in causal attributions for social and physical events, in particular in the likelihood of committing the fundamental attribution error. Culture has also been shown to affect probabilistic thinking, with resulting variations in the use of probability judgments and the calibration of such judgments (e.g., Wright \& Phillips, 1980). Although people in the United States and elsewhere tend to provide confidence judgments for events that are higher than the events' long-run relative frequency of occurrence warrants, there is systematic cross-national variation in the degree of overconfidence. Yates and collaborators have shown greater overconfidence (and, thus, worse calibration) on the part of Asian respondents, with the sole exception of the Japanese, who are better calibrated than Americans and Europeans (Yates, Lee, \& Bush, 1997; Yates et al., 1989). 
The list above is by no means exhaustive, and one could argue that culture has been found to influence psychological processes and behavior in virtually every study that bothered to examine it as a variable. Why, then, is there not greater interest among psychologists in comparative studies that examine the relationship between culture and mind? One explanation for this apparent puzzle is that rigorous cross-cultural investigation of behavior is a very difficult enterprise. Numerous theoretical and practical obstacles need to be overcome-among others, the necessity of conducting research in several languages, with the associated problems of translations of instructions and instruments (Brislin, 1970) and equivalent interpretations of key concepts. Even the best efforts to date have not remained without critics. The seminal work by Segall et al. (1966) was designed to provide a methodologically more sophisticated investigation of the cultural underpinnings of basic perceptual phenomena (such as optical illusions) than did some of the pioneering efforts at the turn of the century (e.g., Haddon, 1901) but has since been faulted for failing to eliminate race and biological evolution as alternative explanations to their hypothesized environmental, sociocultural explanations (Deregowski, 1989; Pollack, 1989). Shweder (1990) goes so far to suggest that there is little utility in adding culture as an explanatory variable to existing models of psychological processes and argues, instead, for a new discipline, cultural psychology, that places culture at the core, rather than at the periphery, of investigations of the mind. Most cross-cultural psychologists, however, would be quite content with a less radical integration of the influence of culture into mainstream (experimental) psychology (Cole, 1996).

A cultural difference is a national (or other subgroup) difference in attitude or behavior that is the result of group differences in stable social structures and/or longstanding values. The differences in social structures and long-standing values may have been shaped by group differences in geography, climate, history, economics, politics, and the way of coping with such environmental differences. However, a cultural difference is neither just a biological/racial difference per se nor a national difference that is the result of only current or transient (economic or political) situational differences.

Political, economic, and technological developments over the last 2 decades promise that considerable benefits can be derived from a fresh advocacy for comparative cross-cultural investigations of individual and group differences in perceptions, values, attitudes, and behaviors. The rapid globalization of manufacturing, commerce, and trade has increased the need for a knowledge base of reliable cross-national differences in perceptions, beliefs, or modes of information processing that can be used, for example, to help in the creation of integrative bargaining solutions in cross-national negotiations (Bontempo, Bottom, \& Weber, 1997). Risk preference - that is, people's preference for (ceteris paribus) riskier or safer choice options - is an important variable in this context.
In this article, we describe a multistudy project designed to examine reasons for observed cross-national differences in risk preference. For a range of risky decisionmaking tasks and different methods of assessing decision makers' degree of risk preference, we have repeatedly found that the financially risky choices made by respondents from the People's Republic of China are significantly less risk averse than those of their counterparts in the United States (Hsee \& Weber, 1999; Weber \& Hsee, 1998). Using this example, we develop the following recommendations for how cross-cultural investigations might be conducted more fruitfully.

First, cross-cultural research should be model based. Just as for any implicitly intracultural study of behavior, cross-cultural investigators should commit themselves to a model of the behavior under study that explicitly specifies possible causal constructs or variables hypothesized to influence the behavior, as well as the relationship between those variables. Furthermore, the model should allow for individual, group, or cultural differences in the value of one or more of these variables or in the relationship between them. Hypothesized causal cultural differences should be on a dimension that can be measured in a wide range of cultures, in the interest of generalizability, and should be shown to serve as either a moderator or a mediator between culture and the observed (betweenand within-culture) behavioral differences.

Second, cross-cultural research should create a causal mosaic. In their data collection, investigators should look for converging evidence for hypothesized cultural effects on behavior by looking at multiple dependent variables and by using multiple methodological approaches.

In the following sections, we will discuss our reasons for each of these recommendations, in turn. To preview those discussions, we will show that the investigation of cross-national differences within the model-based framework described above has the advantage of moving the focus from a simple demonstration of cross-national differences toward a prediction of the behavior in question, including its cross-national variation. To label observed cross-national differences in behavior cross-cultural, we will argue, requires the demonstration of a causal (mediator or moderator) variable that is of long-standing difference in a wide range of cultures, rather than being the result of transient situational factors.

To describe the advantages of investigating crossnational differences on some behavior within a broader cluster of related judgments or actions and from a variety of different methodological perspectives, we suggest the following metaphor. The establishment of a convincing and conclusive causal connection between a cultural variable and some target behavior can be likened to the creation of a mosaic. Each individual tile of the mosaic provides the viewer with a necessary, but only partial, piece of information. The full picture becomes apparent only after all the tiles have been arranged in a particular spatial pattern. In the same way, specific, individual studies of cross-national differences on some dimension can 
often provide only partial answers and may not be able to test between all alternative explanations of the obtained results. In combination, however, where model-based connections between various dependent and predictor variables dictate the particular "spatial" pattern of arrangement, a set of studies often can provide more conclusive evidence about factors (cultural or otherwise) that contribute to the target behavior. Thus, it is crucial to keep the full picture in mind while creating individual tiles. A comprehensive model of the behavior under study that is used as a guide to design individual studies makes it much more likely that those studies will provide cumulative results. It is true, of course, that the mosaic metaphor applies to any empirical investigation, be it cross-cultural or intracultural. However, given their nature, cross-cultural investigations tend to have a far larger number of variables that need to be controlled in order to unambiguously interpret the results of a given study in a certain way, which gives greater urgency to systematic, model-based mosaic building.

So far, we have used the term cross-cultural mostly to refer to cross-national differences that have their source in cultural differences, partly because the example that we will provide to illustrate our claims asks questions about the cultural determinants of cross-national differences between Americans and Chinese. However, our arguments and recommendations are meant to apply equally well to cross-cultural differences that are more broadly defined to include differentiation into subcultures on such factors as gender or ethnicity.

\section{CROSS-CULTURAL RESEARCH SHOULD BE MODEL BASED}

\section{Cross-Cultural Research \\ Should Have a Guiding Theory}

In Hsee and Weber (1999), we found that Americans (students in Columbus, $\mathrm{OH}$ ) were significantly more risk averse in their choices between risky options and sure alternatives than Chinese (students in Shanghai, People's Republic of China), yet both nationals predicted exactly the opposite - that the Chinese would be more risk averse. We focused on the United States and the People's Republic of China because, in many respects, including political systems and traditional cultural values (including the individualism-collectivism continuum measured by Hofstede, 1980), these two countries are extremely different. Both nations also have a significant impact on today's world economy and international affairs, and business and governmental interactions between them have been increasing in recent years (see, e.g., Warner, 1995). Thus, knowledge of any differences in risk preference between members of these two nations would be of theoretical value, as well as of great practical value.

In these initial studies, we used the term risk preference in a theoretically neutral way to simply describe patterns of observed behavior in risky decision situations. We called a person's choices risk averse (to various degrees) if he or she had a tendency to prefer the sure option to the risky option even though the sure payoff was less than the expected value of the risky option. Conversely, we called a choice pattern risk seeking (to various degrees) if the risky option tended to be chosen even though it had an expected value that was less than the sure payoff. Thus defined, risk preference merely describes the curvature of the utility function that could be fit to the observed choice data within an expected-utility framework. However, as has been pointed out by von Winterfeldt and Edwards (1986, p. 256), "those who coined the term risk aversion had in mind the psychological interpretation that someone who prefers the expected value of a gamble over playing the gamble does not like to take risks." Von Winterfeldt and Edwards profess to be uncomfortable with this interpretation, but it is an interpretation with a wide degree of currency among both researchers and the general public. Risk preference, a person's standing on the continuum from risk aversion to risk seeking, is considered to be a stable personality trait by many and one that carries weight, for example, in personnel selection and placement decisions.

Two problems have marred the notion of risk preference as a personality trait. First, different methods of measuring risk preference have been shown to result in different classifications (MacCrimmon \& Wehrung, 1990). Second, even with the same assessment method, individuals have not shown themselves to be consistently risk seeking or risk averse across different domains and situations, both in laboratory studies and in managerial contexts. Despite these complications, there has been a reluctance to relinquish risk attitude as a stable individual difference variable, presumably because of the strong face validity of the construct.

Weber (1998) and Weber and Milliman (1997) showed that another formalization of risk preference allows for a conceptualization of risk attitude that is closer to attitude toward risky options. This formalization is the riskreturn framework of risky choice (see Sarin \& Weber, 1993 ) that originated in finance. Markowitz (1959) modeled people's willingness to pay (WTP) for risky option $X$ as a compromise between the option's return or value (V) and its risk (R) and assumed that decision makers seek to minimize the risk of a portfolio for a given level of expected return:

$$
\mathrm{WT} \mathrm{P}(\mathrm{X})=f(V(\mathrm{X}), R(\mathrm{X}))=V(\mathrm{X})-b R(\mathrm{X}) \text {. }
$$

Risk-return models in finance have equated $V(\mathrm{X})$ with the expected value of option $\mathrm{X}$ and $R(\mathrm{X})$ with its variance, a formalization that is compatible with a quadratic utility function for money and that is still widely used. Recent work has shown that a broad range of utility functions have risk-return interpretations. Different utility functions imply different measures of risk under the assumption of risk aversion and the equation of return with expected value. These generalized risk-return models allow 
for the fact that the perception of the riskiness of risky options may differ between individuals or groups or may differ as a function of the decision domain or context.

Equation 1 implies that differences in risk preference, measured by willingness to pay for $\mathrm{X}$, can come about in at least the following two ways. They may result either from differences in the perception of the riskiness of option X [i.e., from differences in the value of $R(\mathrm{X})$ ] or from differences in the risk-value tradeoff (i.e., from differences in coefficient $b$ ), which provides a measure of attitude toward perceived risk (with a negative coefficient indicating perceived-risk aversion, and a positive coefficient indicating perceived-risk seeking). As we move from simply demonstrating individual or group differences in risk preference to trying to predict and, possibly, modify them, it is useful to have two potential loci for such differences that have different substantive interpretations, rather than being restricted to essentially just redescribing the result as differences in the shape of the groups' utility functions.

In Hsee and Weber (1999), we suggested several alternative explanations (some of them economic/situational, some of them cultural) of our basic finding that Chinese are less risk averse than Americans. One of them we coined the cushion hypothesis: It suggests that people in a socially collectivist society, such as China, are more likely to receive help if they are in need (i.e., they could be cushioned if they fell); consequently, they can afford to take on more risky gambles than members of an individualistic society such as the United States, because they will be cushioned if an extremely bad outcome occurs. Since the cultural collectivism serves as mutual insurance against catastrophic losses, risks faced by members of the collective are, in fact, smaller. The cushion hypothesis thus predicts that cross-national differences in risk preference will be mediated by differences in the term $R(\mathrm{X})$ in Equation 1, as will be further discussed below.

It may be helpful to spell out what we mean by advocating model-based research with reference to our projectcross-national differences in risk preference. Our first choice point was between two formalizations of the basic phenomenon or behavior (risk preference)- that is, between the expected utility and the risk-return framework. Rather than just describing differences in choice patterns in accordance with the expected utility framework, we preferred the risk-return model, because it provided us with a greater number of intervening constructs (risk perception and perceived-risk attitude) for which we could hypothesize and test plausible cultural differences. The model that guides our research is, thus, an elaboration of Equation 1 that posits various cultural and situational influences on the equation's component variables, including the cushion hypothesis. In this sense, modelbased cross-cultural research actually serves to enhance models of behavior, by specifying which predictor variables may be expected to be influenced by culture.

There are other examples in the literature that illustrate how model-based cross-cultural research can broaden our understanding of basic psychological phenomena. One comes from the literature on people's apparent overconfidence in the accuracy of their judgments or decisions, which is a special case of the result referred to in our introduction, that people's probability judgments are often poorly calibrated. Erev, Wallsten, and Budescu (1994) demonstrated that a certain amount of apparent overconfidence in probability judgments can arise as the result of the existence of measurement error, manifesting itself in regression toward the mean. Yet, in a cross-cultural investigation of the phenomenon, Yates et al. (1997) showed-by decomposing confidence judgments into different components (see Yates, 1990), for which different cultural predictions can be made- that overconfidence was indeed a "real," consequential phenomenon, not just a data-analytic artifact.

\section{The Theory Used to Explain \\ Cross-Cultural Differences Should \\ Also Be Able to Explain Other \\ Individual and Group Differences}

Within experimental and cognitive psychology, the study of individual differences has been relatively ignored, in favor of attempts to establish universal processes. Yet, the incorporation of individual differences into cognitive process models (e.g., as parameter differences) can provide additional insights (Bruner, 1990; Thelen, 1995). Data-analytic techniques that implicitly ignore the existence of individual differences can result in drawing incorrect conclusions.

As was discussed in the previous section, individual, group (e.g., gender), and cross-national differences in risk preference are well established (see, also, Bromiley $\&$ Curley, 1992). Using the decomposition of risk preference of Equation 1, these differences in choice could arise from differences in the perception of the riskiness of option $\mathrm{X}$ [i.e., from differences in the value of $R(\mathrm{X})$ ] or from differences in the risk-value tradeoff (i.e., from differences in coefficient $b$ ). According to the cushion hypothesis, the observed American-Chinese differences in risky choice are due to cross-cultural differences in risk perception, $R(\mathrm{X})$. Specifically, the Chinese were expected to perceive the same risky options to be less risky than their American counterparts, because of their collectivist mutual "insurance." This prediction was tested in recent experiments by Weber and Hsee (1998). Respondents' risk perception was measured by a numerical response to the following question: "How risky is this option, on a scale from 0 (no risk at all) to 100 (extremely risky)?" As was predicted, Chinese risk ratings were significantly lower than those of the Americans. Individualsubject regressions, using Equation 1, that predicted the prices a person paid for a set of risky investment options as a function of the options' expected value and that person's judgments of the options' riskiness showed that there were no significant cultural differences in risk-value tradeoff coefficient $b$. After factoring out cultural differences in the perception of the riskiness of choice op- 
tions, both nationalities were equally perceived-risk averse and lowered the prices they were willing to pay for risky options by the same amount for each unit of perceived risk.

Brachinger, Schubert, Weber, Brown, and Gysler (1997) obtained very similar results when investigating the locus of gender differences in risk preference. Men and women have been found to choose differently among risky options - for example, in pension investment allocation decisions (Bajtelsmit, Bernasek, \& Jianakoplos, 1997). Women's allocations tend to be more risk averse, in the expected-utility meaning of the phrase, and women also seem to display more expected-utility risk aversion in risky activities, such as smoking, seat belt usage, and speeding (Hersch, 1996). At the same time, Slovic and collaborators (see Slovic, 1997, for a summary) have documented gender differences in the perception of the riskiness of such activities and of risky choice options, with women perceiving the same risks to be greater than men perceive them. Thus, it appears that gender differences in choice are either partially or entirely the result of differences in the perception of the riskiness of the choice options and that perceived-risk attitude (i.e., the risk-value tradeoff coefficient $b$ of Equation 1) may not differ as a function of gender. To test this hypothesis, Brachinger et al. collected data from both male and female respondents about their willingness to pay for a set of financial investment options and about their perception of the riskiness of these options and replicated previously reported gender differences on both judgments. They then obtained an estimate of the perceived-risk attitudes of men and women by fitting the regression model of Equation 1 to the data. There was no significant difference in the value of any of the regression coefficients and, particularly, none for perceived-risk attitude coefficient $b$. In other words, gender differences in willingness to pay for the risky investment options were mediated by differences in the perception of the options' riskiness. Women perceived those risks to be higher than men and, subsequently, were willing to pay less for the options.

\section{The Theory Should Be Tested By Showing the Mediating or Moderating Role of Cultural Differences}

In Hsee and Weber (1999), we tested the cushion hypothesis in yet another way, by comparing the risk preferences of Americans and Chinese in different decision domains (namely, investment, medical, and academic decisions). We predicted that the Chinese would be less risk averse than the Americans only in the investment domain, and not in the other domains, because the collectivist cushion cannot cure illnesses or fix course grades. Our results confirmed this prediction. In that study, we also measured the size and quality of each respondent's social network. This served as a (successful) manipulation check on our assumption that Chinese have larger social networks than Americans, on which they can call for financial support. It also allowed us to (successfully) test the mediating effect of the size of the social network on risk preference. Although we replicated our previous result that risk preference was significantly different between cultures, culture became a nonsignificant predictor after we added to the equation such social network information as the number of people a person could call on for financial support.

Examples of cultural differences that moderate basic psychological processes can be found in social psychology. Brockner and Chen (1996) demonstrated the importance of self-esteem and self-construal as variables that moderate people's behavior in response to negative feedback by studying these relationships in two countries (the United States and the People's Republic of China) with cultural differences in self-construal. Similarly, Chen, Brockner, and Katz (1998) showed that cultural differences in individual-collective primacy (i.e., the relative weight individuals give to their personal interests, rather than to their in-group's interests) moderated how respondents from the People's Republic of China and the United States reacted to discrepancies between their own performance and their in-group's performance. In both studies, the identification of a causal moderating variable on which members of different cultures can and have been shown to differ not only put into question the generality of results obtained from American respondents, but provided a more general theoretical understanding of the behavior under investigation.

\section{CROSS-CULTURAL RESEARCH SHOULD CREATE A CAUSAL MOSAIC}

\section{Use of Multiple Dependent Variables}

Cross-cultural research can be conducted on two different levels. On the first level, the goal is to secure differences in overt behaviors between members of different cultures. On the second level, the goal is to identify underlying cultural values that drive overt behavioral differences. McDaniels and Gregory (1991) rightly voiced concern that many researchers fail to distinguish between these two levels. That is, national differences are often treated as cultural in origin, without any attempt being made to distinguish between cultural and situational determinants. Such a distinction is not always easy to maku. Johnson (1991) suggests the strategy of accepting a crossnational difference in a given behavior as being cultural in origin only if it is paralleled by differences in other, related behaviors that can be expected to have different situational determinants. Following this strategy, we developed predictions about the consequences of Hsee and Weber's (1999) cushion hypothesis for behaviors other than risk taking-in particular, for perceptions of the riskiness of risky options. Our own (Weber \& Hsee, 1998) and other research (Bontempo et al., 1997; Palmer, 1996; Slovic, 1997) was able to document cross-cultural differences in risk perception that are consistent with the cultural cushion hypothesis-for example, lower perceptions 
of the riskiness of financial instruments by members of socially collectivist cultures.

\section{Use of Multiple Methodological Approaches}

More than in other research domains, conclusive insights in cross-cultural research require a combination of methods-that is, a mosaic of approaches at the level of data collection. It is important to know, but not easy to establish, whether observed national differences in behavior are truly cultural - that is, are the result of longstanding differences in cultural norms and values that are not easily modified - or whether they are more malleable and transient because they result from current situational circumstances. Weber, Hsee, and Sokolowska (1998) demonstrated that the comparative analysis of cultural products can provide converging evidence to help answer this question. Norms and values operating in a given culture affect the behavior of members of that culture. In addition to that, the events and circumstances that, over many generations, create those values as a cultural adaptation leave their trace and are reflected by a variety of cultural products. Such collective products that store and transmit cultural wisdom include a culture's proverbs, which provide advice about recommended courses of action, its literature, its philosophy, and its art. If national differences in some behavior are the consequence of longstanding differences in cultural values, rather than differences in current economic or political circumstances, they should also be reflected in cultural products, such as the culture's proverbs. If they are exclusively the product of the current environment, they will not be reflected in cultural documents, especially if the instrumental characteristics of the current environment are of recent origin.

In Weber et al. (1998), we reported the results of two studies that utilized an unconventional method-namely, a comparative content analysis of national proverbs - to gain insight into the sources of cross-cultural differences in risk taking. There were three main findings. All three lend support to the cushion hypothesis proposed by Hsee and Weber (1999), according to which members of socially collectivist cultures can afford to take greater financial risks, since their social networks ensure them against catastrophic outcomes, but for the same reason, need to use greater caution when it comes to social risks. First, regardless of the nationality of the raters, Chinese proverbs seem to provide greater risk-taking advice than do American proverbs. Prior research (Hsee \& Weber, 1999; Weber \& Hsee, 1998) showed that Chinese participants are less risk averse in financial and other material decisions than their American counterparts, but did not conclusively answer whether these differences in behavior reflect long-standing differences in cultural values or differences in the current socioeconomic or political situation between these countries. The finding that Chinese proverbs (which have been accumulated over many centuries) endorse risk taking more than do American proverbs suggests that observed difference in risk taking stems, at least in part, from long-standing differences in cultural values. The fact that German proverbs are similar in advocated risk taking to proverbs from China (a culture with which Germany shares some values, including a similar degree of social collectivism) and not to proverbs from the United States (a culture with which Germany shares similar socioeconomic conditions, its political system, and other cultural values, a result of a common heritage) suggests that national proverbs related to risk and risk taking do, indeed, reflect cultural differences related to social collectivism.

Second, regardless of the cultural origin of the proverbs, Chinese raters perceived the same proverbs to provide greater risk-taking advice than did American raters, but only for the domain of financial risks, and not for the domain of social risks. Study 2 showed that this difference in the consequences of risk taking between domains does not only affect a culture's proverbs per se (after all, many proverbs can be applied to both financial and social risks), but also appears to affect the interpretation of such proverbs in different decision contexts. Thus Chinese raters perceived the same proverbs as providing significantly more risk-seeking advice in the context of financial risk than in the context of social risk, whereas American raters did not show such sensitivity to the decision domain. Long-standing and (as shown by Study 1) persisting cultural differences in social connectedness predict the direction of the observed differential attitude of Chinese raters to social and financial risks.

The third result was that American proverbs are systematically judged to be more applicable to financial-risk decisions than to social-risk decisions, whereas Chinese proverbs are much closer to being considered to be equally applicable to the two domains. This finding is consistent with the notion that China is (and has long been) a collectivist society and America an individualistic one. The proverbs produced by these two cultures over time reflect the fact that social concerns are rated as equal to financial or materialistic concerns in collectivist cultures, but are of smaller importance in individualist cultures.

Other examples of the utility of analyzing cultural products to provide converging evidence for cultural difference hypotheses can be found in McClelland (1961) and Gaenslen (1986). McClelland found independent support for cultural differences in the need for affiliation in his content analysis of elementary school primers from different countries. Gaenslen established cultural differences in the conceptualization of decision problems and of their resolution in the fiction produced by authors in different cultures.

\section{CONCLUSIONS}

Using, as our example, the recent observation that there are systematic cross-national differences in risk preferences that appear to be mediated by cultural differences in social collectivism, we have tried to make an argument for a set of recommendations for how fruitful cross-cultural research ought to be conducted. We suggest that, given its importance and inherent difficulty, conclusive cross-cultural research requires an even more 
carefully thought-out theoretical rationale for individual studies and their interrelationship than does psychological research in general. Our recommendation is for model-guided mosaic building, which provides for cumulative results from multiple studies designed to investigate different aspects and determinants of the behavior of interest. We suggested that the identification of crossnational variation in some behavior is only of theoretical interest if it furthers our understanding of the causal variables and structure that give rise to the behavior. An understanding of the causal structure is also crucial to making such results practically useful. It provides clues as to whether and how observed cross-national differences in behavior are modifiable and makes predictions for behavior in cultures that have not been directly studied.

\section{REFERENCES}

Bajtelsmit, V. L., Bernasek, A., \& Jianakoplos, N. A. (1997). Gender differences in pension investment allocation decisions. Working Paper in Economics and Political Economy, Colorado State University, Fort Collins.

BONTEMPO, R. N., BotToM, W. P., \& WEBER, E. U. (1997). Cross-cultural differences in risk perception: A model-based approach. Risk Analy. sis, 17, 479-488.

Brachinger, H.-W., Schubert, R., Weber, E. U., Brown, M., \& GYSLER, M. (1997). Gender differences in risky choice: A theoretical framework and methodological approaches. Working Paper, Institut für Wirtschaftsforschung, ETH Zurich.

BRISLIN, R. W. (1970). Back-translation for cross-cultural research Journal of Cross-Cultural Psychologv, 1, 185-216.

BROCKNER, J., \& CHEN, Y.-R. (1996). The moderating roles of self-esteem and self-construal in reaction to a threat to the self: Evidence from the People's Republic of China and the United States. Journal of Personality \& Social Psychology, 71, 603-615.

Bromiley, P., \& Curley, S. P. (1992). Individual differences in risk taking. In J. F. Yates (Ed.), Risk-taking behavior (pp. 87-132). Chichester, U.K.: Wiley.

Bruner, G. (1990). Acts of meaning. Cambridge, MA: Harvard University Press.

Chen, Y.-R., Brockner, J., \& Katz, T. (1998). Toward an explanation of cultural differences in in-group favoritism: The role of individual versus collective primacy. Journal of Personality \& Social Psychology, 75, 1490-1502.

COLE, M. (1996). Cultural psychology: A once and future discipline. Cambridge, MA: Harvard University Press.

DeregowSKI, J. B. (1989). Real space and represented space: Crosscultural perspectives. Behavioral \& Brain Sciences, 12, 51-119.

Erev, I., Wallsten, T. S., \& Budescu, D. V. (1994). Simultaneous over-and underconfidence: The role of error in judgment processes. Psychological Review, 101, 519-527.

GAENSLEN, F. (1986). Culture and decision making in China, Japan, Russia, and the United States. World Politics, 39, 87-103.

HADDON, A. C. (ED.) (1901). Report of the Cambridge anthropological expedition to the Torres Straits (Vol. 2). Cambridge: Cambridge University Press.

HersCH, J. (1996). Smoking, seat belts, and other risky consumer decisions: Differences by gender and race. Managerial \& Decision Economics, 11, 471-481.

HoFstede, G. H (1980). Culture's consequences: International differences in word-related values. Beverly Hills, CA: Sage.

HsEe, C. K., \& Weber, E. U. (1999), Cross-national differences in risk preference and lay predictions. Journal of Behavioral Decision Making, 12, 165-179.

JoHNSON, B. B. (1991). Risk and culture research: Some cautions. Journal of Cross-Cultural Psychology, 22, 141-149.

MacCrimmon, K. R., \& Wehrung, D. A. (1990). Characteristics of risk taking executives. Management Science, 36, 422-435.
Markowitz, H. M. (1959). Portfolio selection. New York: Wiley.

Markus, H. R., \& Kitayama, S. (1991). Culture and self: Implications for cognition, emotion and motivation. Psychological Review, 98, 224-253.

MCClelland, D. C. (1961). The achieving society. Princeton, NJ: Van Nostrand.

MCDaniels, T. L., \& Gregory, R. S. (1991). A framework for structuring cross-cultural research in risk and decision making. Journal of Cross-Cultural Psychology, 22, 103-128.

Morris, M. W., \& PeNG, K. (1994). Culture and cause: American and Chinese attributions for social and physical events. Journal of Personality \& Social Psychology, 67, 949-971.

Palmer, C. G. S. (1996). Risk perception: An empirical study of the relationship between worldview and the risk construct. Risk Analysis, $16,717.724$

POLLACK, R. H. (1989). Pictures, maybe; illusions, no. Behavioral \& Brain Sciences, 12, 92-93.

SARIN, R. K., \& WEBER, M. (1993). Risk-value models. European Journal of Operations Research, 70, 135-149.

Segall, M. H., Camprell, D. T., \& Herskovitz, M. J. (1966). The influence of culture on visual perception. Indianapolis: Bobbs-Merrill.

Segall, M. H.. Dasen, P. R., Berry, J. W., \& Poortinga, Y. H. (1990). Human behavior in global perspective: An introduction to crosscultural psychology. New York: Pergamon.

Shweder, R. A. (1990). Cultural psychology: What is it? In J. W. Stigler, R. A. Shweder, \& G. Herdt (Eds.), Cultural psychology: Essays on comparative human development (pp. 35-48). New York: Cambridge University Press.

Stovic, P. (1997). Trust, emotion, sex, politics, and science: Surveying the risk-assessment battlefield. In M. Bazerman, D. Messick, A. Tenbrunsel, \& K. Wade-Benzoni (Eds.), Psychological perspectives to environmental and ethical issues in management (pp. 277-313). San Francisco: Jossey-Bass.

Thelen, E. (1995). Time-scale dynamics and the development of an embodied cognition. In R. F. Port \& T. van Gelden (Eds.), Mind as motion: Explorations in the dynamics of cognition. Cambridge, MA: MIT Press.

von Winterfeldt, D., \& Edwards, W. (1986). Decision analysis and behavioral research. Cambridge: Cambridge University Press.

WARNER, J. (1995, October 30). The world is not always your oyster: Why cross-border mergers so often come to grief. Business Week, pp. 132-134.

WEBER, E. U. (1998). Who's afraid of a little risk? New evidence for general risk aversion. In J. Shanteau, B. A. Mellers, \& D. Schum (Eds.), Decision research from Bayesian approaches to normative systems: Reflections on the contributions of Ward Edwards (pp. 5364). Norwell, MA: Kluwer Academic Press.

Weber, E. U., \& Hsee, C. K. (1998). Cross-cultural differences in risk perception, but cross-cultural similarities in attitude toward perceived risk. Management Science, 44, 1205-1217.

Weber, E. U., Hsee, C. K., \& Sokolowska, J. (1998). What folklore tells us about risk and risk taking: A cross-cultural comparison of American, German, and Chinese proverbs. Organizational Behavior \& Human Decision Processes, 75, 170-186.

Weber, E. U., \& Milliman, R. (1997). Perceived-risk attitudes: Relating risk perception to risky choice. Management Science, 43, 122-143.

Wright, G. N., \& PhIL LIPS, L. D. (1980). Cultural variation in probabilistic thinking: Alternative ways of dealing with uncertainty. International Journal of Psychology, 15, 239-257.

YATES, J. F. (1990). Judgment and decision making. Englewood Cliffs, NJ: Prentice-Hall.

YATES, J. F., LEe, J.-W., \& Bush, J. G. (1997). General knowledge overconfidence: Cross-national variations, response style, and "reality." Organizational Behavior \& Human Decision Processes, 70, 87-94.

Yates, J. F., ZhU, Y., Ronis, D. L., Wang, D. F., Shinotsuka, H., \& TODA, W. (1989). Probability judgment accuracy: China, Japan, and the United States. Organizational Behavior \& Human Decision Processes, 43, 147-171.

(Manuscript received July 16, 1998;

revision accepted for publication March 23, 1999.) 